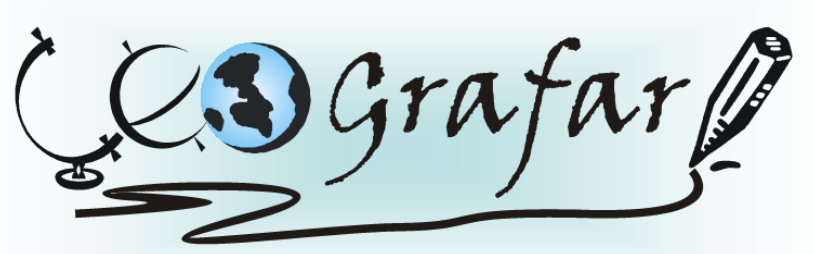

Revista Eletrônica do Programa de Pós-Graduação em Geografia - UFPR

\title{
GLOBALIZAÇÃO E POBREZA: O CASO DO BRASIL
}

\author{
FERNANDO ANTONIO SALOMÃO LOCH ${ }^{1}$
}

\begin{abstract}
Resumo: A conceituação dos termos globalização e pobreza é complexa. Apesar dos estudos a respeito do primeiro termo serem recentes e, muitas vezes, controversos, a globalização, no sentido mais comumente utilizado, refere-se a um fenômeno sócio-econômico de integração entre os países ocorrido no século XX. No caso do Brasil, mais exatamente durante a sua abertura econômica. A pobreza, por sua vez, deve ser entendida como a escassez de uma gama de variáveis que vai além da análise da renda. Diversos autores defendem a idéia de que a globalização traz a pobreza. $O$ Brasil aderindo a ela, tenderia a empobrecer. Entretanto, analisando dois trabalhos, do IPEA e do PNUD, respectivamente, verificou-se que diversos indicadores sociais melhoraram durante o período que o país esteve exposto ao fenômeno. Uma vez que os críticos comumente não se baseiam em dados estatísticos, infere-se que seus trabalhos são influenciados por pressupostos ideológicos.
\end{abstract}

Palavras chave: Globalização; Indicadores Sociais; Pobreza.

\section{GLOBALIZATION AND POVERTY: THE CASE IN BRAZIL}

Abstract: The conceptualization of the terms globalization and poverty is complex. Although studies about the first therm are recent and often controversial, globalization, in the most commonly used way, refers to a phenomenon of social-economic integration among coutries, occurred in the twentieth century. In case of Brazil, during the economic openness. By its turn poverty must be understood as the lack of a range of variables that goes beyond the income analysis. Several authors advocate the idea that globalization takes to poverty. Brazil, sticking to it, would tend to impoverish. Analysing two research papers, from IPEA and UNDP, respectively, was possible to verify, however, that many social indicators improved during the time the country was exposed to the phenomenon. Since, critics aren't based on their opinion on statistical data most of the time, it seems that their work is influenced by ideological assumptions.

Key Words: Globalization; Poverty; Social Indicators

\section{INTRODUÇÃO}

A globalização traz pobreza. Esta afirmação é constantemente vista em estudos acadêmicos e livros didáticos de diversos autores, muitos desses, geógrafos. Em alguns de maneira explícita, em outros de maneira implícita. O Brasil, segundo esses pensadores, como país integrante da globalização, tenderia a empobrecer. O objetivo deste artigo é justamente testar essa tese.

\footnotetext{
${ }^{1}$ Bacharel em Geografia pela UFPR (2009). Atualmente concluindo a Licenciatura no mesmo curso também pela UFPR.
} 
Para isso, antes de tudo, é necessário entender os dois substantivos da afirmação inicial: globalização e pobreza. Pela juventude do primeiro e a subjetividade do segundo, os dois conceitos tendem a ser controversos. A pobreza, muitas vezes, torna-se subjetiva devido à falta de discussões conceituais, apesar da presença do termo em diversos estudos sociais. À seção um cabe a tarefa de discutir a sua definição e como pode ser medida.

A globalização, na semântica mais comum, ainda é um fenômeno recente. Entretanto, diversos trabalhos têm tentado buscar um retrato a altura de sua complexidade. A seção dois apresentará alguns desses trabalhos e buscará encontrar concordâncias entre os autores, tentando determinar quando o fenômeno efetivamente começou no Brasil.

Dando sequência, a seção três apresenta trabalhos de autores que criticam a globalização, entre eles, o influente geógrafo Milton Santos. Após a subsecção introdutória chamar a atenção para as principais características desses trabalhos, suas principais premissas serão destacadas separadamente.

Já a seção quatro apresenta os resultados de duas pesquisas que procuram analisar a pobreza no país; a primeira analisa a evolução de dois indicadores de pobreza, o Índice de Gini e o T de Theil, e também faz uma comparação da evolução do Brasil frente outros países; a segunda demonstra dados de variáveis como a mortalidade infantil de 1991 e 2000, visando traçar a evolução do desenvolvimento humano no país.

Finalmente, na conclusão, estará o resultado da tese da avaliação dos autores selecionados à luz das pesquisas mencionadas, assim como o resultado da análise da conceituação dos termos "globalização" e "pobreza" e suas possíveis vinculações com o resultado do trabalho. Com isso, o presente artigo espera cumprir a tarefa de prestar subsídios à compreensão da possível relação que existe entre a globalização e a pobreza, no caso do Brasil. 


\section{POBREZA}

\section{Conceito e Indicadores}

Segundo o Dicionário Essencial de latim-português e português-latim (2001), a palavra "pobre" tem origem no adjetivo pauper, que significa pobre; pequeno; estéril; pouco abundante. Originalmente, utilizava-se a palavra para designar solo ou gado que não produzia o desejado. A princípio, as discussões acerca da pobreza a tratavam como uma penúria natural e imutável. A pobreza, unidimensional, era sinônimo de insuficiência de alimento para a manutenção do corpo.

O enfoque da privação relativa passou a ser referenciado no início dos anos 80. Este ponto de vista buscava uma formulação científica e a capacidade de comparação entre estudos internacionais, nos quais destacava o aspecto social.

O ganhador do prêmio Nobel de economia, Amartya Sen (2000), procura ir além da simples observação da renda e trata a pobreza como uma privação das capacidades elementares de um indivíduo. Para ele, a capacidade seria um tipo de liberdade que o cidadão teria se estivesse adequadamente nutrido, livre de doenças evitáveis e possuísse respeito próprio para participar da vida em comunidade. Seu conceito, entretanto, não desqualifica a renda, pois o nível desta pode ser a razão primeira da privação da capacidade.

Os conceitos de pobreza nos dias atuais tentam captar essa complexa escassez, que representa diversas necessidades. Sônia Rocha (2007) apresenta, dentro de um mesmo parágrafo, tanto uma explicação mais simples como uma mais complexa.

Entretanto, do que se trata quando, especificamente, nos referimos à pobreza? Pobreza é um fenômeno complexo, podendo ser definido de forma genérica como a situação na qual as necessidades não são atendidas de forma adequada. Para operacionalizar essa noção ampla e vaga, é essencial especificar que necessidades são essas e qual nível de atendimento pode ser considerado adequado. A definição relevante depende basicamente do padrão de vida e da forma como as diferentes necessidades são atendidas em determinado contexto socioeconômico. Em última instância, ser pobre significa não dispor dos meios para operar adequadamente no grupo social em que se vive. (P. 9) 
Nesta conceituação pode-se notar uma dualidade. Primeiro Rocha (2007) descreve a pobreza como um fenômeno complexo, uma situação de escassez na qual é necessária a definição do produto, assim como a quantidade. Entretanto, a tarefa de classificar os produtos e suas quantidades como imprescindíveis ou prescindíveis, é impossível de ser imparcial da inclinação pessoal. No fim do parágrafo, frente à tarefa complexa de definir a pobreza, lança uma alternativa mais simples e generalista. A pobreza seria não possuir os meios para operar adequadamente na sociedade em que se vive.

As necessidades não necessariamente são as mesmas em todos os países, em todas as culturas. Numa sociedade hipotética, pobreza é não conseguir obter o produto $\mathrm{x}$, em outra, para ser pobre a pessoa tem que possuir menos de três unidades do produto x. Quanto mais rica for a nação, mais o conceito de pobreza se distanciará das necessidades básicas de sobrevivência. É possível que um indivíduo pobre na Dinamarca, não seja considerado pobre no México. Entretanto, mesmo dentro de um mesmo grupo, é impossível afirmar que exista um juízo que seja unânime ao relacionar um conjunto de bens e serviços que sejam imprescindíveis à vida de cada um de seus membros.

Com base nessas diferenças torna-se necessária uma distinção entre o enfoque da pobreza como algo relativo ou como algo absoluto. A pobreza relativa está ligada com a desigualdade da distribuição de renda porque define como pobre aquele que tem algum atributo a menos do que todos os outros, dentro de uma mesma sociedade. Por sua vez, a pobreza absoluta ocorreria quando houvesse uma fixação de padrões para o nível mínimo ou suficiente de necessidades, mais conhecida como linha ou limite da pobreza (CRESPO; GUROVITZ, 2002); ou seja, seria considerada pobre a porcentagem da população que se encontraria abaixo desse padrão de vida mínimo, numa determinada época.

Os indicadores são ferramentas importantes para o estudo da pobreza, pois correspondem à descrição por meio de números de um determinado aspecto da realidade (KAYANO; CALDAS, 2002). Estes permitem, por exemplo, acompanhar mudanças na qualidade de vida de uma região num determinado período de tempo, tornando possível testar a eficácia de políticas econômicas sobre a população. $\mathrm{O}$ 
Coeficiente de Gini é uma medida matemática associada à curva de Lorenz, que fornece a distribuição da frequência acumulada de um evento. Consiste num número entre zero (0) e um (1), onde zero é uma situação onde todos possuem a mesma renda e um é onde apenas uma pessoa possui renda e nenhuma outra possui. Já o coeficiente $\mathrm{T}$ de Theil compreende a razão entre as médias aritméticas e geométricas da renda familiar per capita média. Assim como no índice de Gini, quanto maior o valor, mais concentrada estaria a renda e vice-versa.

Sendo assim, conceituar a pobreza é uma tarefa ao mesmo tempo simples e complexa. Do ponto de vista simples, a pobreza poderia ser conceituada como uma situação em que o indivíduo não possui meios de saciar as necessidades de uma vida considerada normal pela sociedade na qual vive. Esse prisma traz o enfoque da pobreza relativa, pois classifica o cidadão em relação aos outros. Por esse mesmo motivo, essa visão se relaciona intimamente com a distribuição de renda. $O$ indivíduo é rico ou pobre em comparação com os outros habitantes da mesma sociedade.

A tarefa se torna complexa quando se questiona quais seriam as necessidades básicas do ser humano. Essa visão se relaciona diretamente com o conceito de pobreza absoluta, pois tenta definir um padrão de vida geral. A dificuldade é que esse padrão estaria à mercê de um juízo humano que estipularia produtos e quantidades que deveriam atender toda a sociedade em questão. Tal tarefa é penosa, senão impossível, quando se leva em conta a hetereogenidade de costumes de uma sociedade moderna. Por exemplo, uma medida que fosse adotada para todo o Brasil negligenciaria diferenças como as variações no custo de vida entre as diversas regiões do país.

Deste modo, a pobreza está além da simples questão alimentar, pois ela é pontuada por diversos fatores que permitiriam um mínimo de conforto. A dificuldade reside em padronizar esse conforto para a diversidade humana. Entretanto, para fins de pesquisa e estudo é necessário algum tipo de medida que permita fazer comparações e análises. Os indicadores de pobreza se baseiam na distribuição de renda e, ainda que não sejam retratos fiéis, podem fornecer um reflexo mais 
completo da vida humana moderna, permitindo uma análise mais próxima do ideal do fenômeno chamado pobreza.

\title{
GLOBALIZAÇÃO
}

\section{Conceito}

O sociólogo Octavio lanni (1994) afirma que existe um conceito historicamente novo e ao mesmo tempo impreciso, um desafio epistemológico. Os processos e as estruturas, sob diferentes prismas, se desenvolvem em escala mundial, de modo que as reflexões sobre sociedades nacionais não seriam suficientes para compreender o fenômeno.

\begin{abstract}
Nesta altura da história, no declínio do século $X X$ e limiar do $X X I$, as ciências sociais se defrontam com um desafio epistemológico novo. $O$ seu objeto transforma-se de modo visível, em amplas proporções e, sob certos aspectos, espetacularmente. Pela primeira vez, são desafiadas a pensar o mundo como uma sociedade global. As relações, os processos e as estruturas econômicas, políticas, demográficas, geográficas, históricas, culturais e sociais, que se desenvolvem em escala mundial, adquirem preeminência sobre as relações, processos e estruturas que se desenvolvem em escala nacional, o pensamento científico, em suas produções mais notáveis, elaborado primordialmente com base na reflexão sobre a sociedade nacional, não é suficiente para apreender a constituição e os movimentos da sociedade global. (P. 01)
\end{abstract}

Segundo Helena Maria Martins Lastres (1997), o termo globalização surgiu nas escolas de administração dos EUA durante os anos 80. Para ela, a palavra continha uma ideologia que junto a uma vulgarização do termo, criou uma certa rejeição do meio científico, de início.

Para Prado (2003), pode-se perceber quatro linhas básicas de compreensão do fenômeno:

1) Globalização como uma época histórica;

2) Globalização como um fenômeno sociológico de compressão do espaço e tempo; 
3) Globalização como hegemonia dos valores liberais;

4) Globalização como fenômeno sócio-econômico.

Para a primeira linha, Prado cita como exemplo a posição do jornalista Ignácio Ramonet (1998), que define Globalização como a principal característica do ciclo histórico que começou após as quedas do muro de Berlim e da União Soviética e redefiniu conceitos políticos como Estado-nação e soberania.

Já como exemplo da segunda linha, Prado diz que David Harvey (1989) acredita que a tecnologia do mundo moderno permitiu uma compressão do espaço e do tempo, e que, segundo suas palavras, essa compressão favorece o capital globalizado e desfavorece o poder dos trabalhadores. Entretanto, isso poderia levar a situações onde o localismo e o nacionalismo seriam mais estimulados do que o internacionalismo.

Como hegemonia dos valores liberais, esta idéia pode tomar dois rumos: como criação ideológica para legitimar a atual ordem internacional ou como fenômeno real e observável. No primeiro rumo, Prado cita como exemplo Paul Hirsch (1998) e infere que a economia mundial seria dominada pela Europa, Japão e América do Norte. $\mathrm{O}$ investimento direto estrangeiro estaria concentrado apenas em alguns países e a maioria das empresas tidas como transnacionais, na verdade, seriam multinacionais vinculadas culturalmente e economicamente ao país sede. Já como exemplo do segundo rumo, Prado utiliza Francis Fukyama (1992) e considera a globalização como uma universalização de valores da democracia liberal e da ordem econômica baseada no modelo de mercado americano.

Prado (2003) afirma que a idéia de fenômeno socioeconômico é defendida por autores como Reinaldo Gonçalves (1999), onde a globalização estaria ocorrendo ao longo das últimas décadas, fruto da interação de três processos: a expansão extraordinária dos fluxos internacionais de bens, serviços e capitais; o acirramento da concorrência nos mercados internacionais e a maior integração entre os sistemas econômicos nacionais.

Finalmente, Prado elabora o seu próprio conceito de globalização, tomando como perspectiva o último dos quatro pontos de vista apresentados: 
Definimos globalização como o processo de integração de mercados domésticos, no processo de formação de um mercado mundial integrado. Em vista desta definição, incluimo-nos, portanto, entre os defensores da idéia de globalização como fenômeno socio-econômico. (P. 04)

Lastres (1997), por sua vez, se põe a enumerar as principais críticas aos estudos ligados à globalização:

1) As análises geralmente priorizam alguns aspectos específicos como os econômicos, tecnológicos, sociais, culturais ou outros, sendo raros os estudos que reconhecem e abrangem o conjunto completo das relações.

2) A maioria dos estudos elege uma determinada perspectiva de análise. Podem ser as superpotências, o Terceiro Mundo, as empresas, a nova divisão internacional de trabalho e produção, entre outros.

3) Em geral, os estudos tratam de análises comparativas entre nações e continentes; tecnologias, setores, bens ou serviços; regimes políticos e políticas governamentais.

4) Tais estudos, geralmente, baseiam-se em teorias específicas desenvolvidas para explicar outros fenômenos que não a globalização, identificandose, inclusive, tentativas de combinar elementos de diferentes teorias.

Para a pensadora, inclusive existe uma linha que prega que não é suficiente transferir conceitos, categorias e interpretações baseadas em outros paradigmas do conhecimento sob o risco de utilizar materiais obsoletos ou que exigem reelaborações.

Pode-se então inferir que a Globalização, apesar de ser um fenômeno observável, ainda possui uma conceituação imprecisa e carente de mais investigação. Entretanto existem algumas convergências em torno do termo. A globalização pode ser vista sob diversos prismas, sendo que o mais utilizado a entende como um fenômeno sócio-econômico. Nesse sentido, apesar de historicamente o homem globalizar desde os primórdios da civilização, a globalização, sob a semântica atual, teve início nas últimas décadas do século XX. 
O seu motivador foi o fim da bi-polarização mundial agindo em conjunto com 0 vertical avanço tecnológico ocorrido durante a segunda metade do século passado. Esses dois fatores levaram à hegemonia da economia capitalista e a uma crescente facilidade de intercâmbio de diversos fatores entre os países, levando a uma maior integração econômica entre todos os pontos geográficos do planeta.

\section{Brasil na Globalização}

Por globalização ficou entendido que se trata de um fenômeno de integração econômica ocorrido nos fim do século XX. Assim, podemos relacionar a inserção mais efetiva do Brasil na Globalização com a década de 90, pois nesse período foram aplicadas políticas que visavam diminuir a influência do Estado na economia e promover a "integração competitiva" do país ao cenário econômico internacional (DINIZ FILHO, 2000).

Essas diretrizes tiveram início no governo de Fernando Collor, entre 19901992. O plano Collor combinava liberação fiscal e financeira com medidas radicais para estabilização da inflação. O plano previa a eliminação de vários tipos de incentivos fiscais e uma flexibilização do câmbio, a fim de incentivar uma progressiva abertura econômica. Foi criado um cronograma que visava a redução progressiva das tarifas aduaneiras.

A inserção do país na economia internacional se consolidou efetivamente no plano econômico seguinte, o Plano Real. Este passou por uma gestação no governo de Itamar Franco (1992-1993) e teve continuidade no governo de Fernando Henrique Cardoso (1994-2002). A sua pauta continha a desindexação da economia, as privatizações, o equilíbrio fiscal, a abertura econômica e políticas monetárias restritivas (FIÚZA, 2006).

Infere-se que o Brasil passou a fazer parte do cenário de integração econômica própria do fenômeno sócio-econômico chamado de globalização quando os governos da década de 90 mudaram o rumo da economia nacional. O novo modelo proposto baseava-se conceitualmente em uma menor intervenção do Estado na 
economia, e seu pleno funcionamento dependia da interação com outras economias internacionais. Para isso, a máquina pública foi reduzida por diversas privatizações enquanto barreiras ao comércio exterior foram reduzidas ou eliminadas. Segundo Diniz Filho, era o momento da implantação do modelo de integração competitiva no Brasil. A justificativa era gerar um mercado mais dinâmico, que tomaria o lugar do governo como principal propulsor da modernização e do crescimento econômico do país.

\section{EFEITOS DA GLOBALIZAÇÃO}

\section{Os Críticos}

No Brasil existe uma extensa bibliografia que enxerga a globalização como um fenômeno que leva à deterioração das condições sócio-econômicas da população. Nesses trabalhos, a globalização seria a personificação do capitalismo e suas contradições.

Alberto Carlos Almeida, em seu artigo "O Brasil no Final do Século XX: Um Caso de Sucesso" (1998), cita a expressão de Nelson Rodrigues, Complexo de ViraLata, para explicar o sentimento de diversos estudos sobre o Brasil. Haveria um sentimento de que o país não melhora, apenas piora, fundamentado em pouca, por vezes nenhuma, base empírica. Esse sentimento já seria intrínseco à identidade nacional. Apesar de não encontrar fundamento nas estatísticas sócio-econômicas, esse pensamento estaria contaminando a literatura acadêmica.

Não se pode afirmar que um complexo de inferioridade dessa natureza contamine a literatura acadêmica recente. Todavia, há vários exemplos de diagnósticos catastrofistas e pessimistas sobre o país, que muitas vezes são possíveis porque a mudança para melhor não é percebida, ou quando o é não chega a ser valorizada. Vale ressaltar, porém, que análises pessimistas não são específicas ao que é produzido no Brasil. (P.02)

Analisando estudos brasileiros, Almeida cita ainda o trabalho de Wanderley Guilherme dos Santos (1986). Para Santos, o problema não seria apenas desconcentrar o topo da pirâmide, mas principalmente resgatar os indigentes e 
miseráveis das periferias urbanas. O estudioso também cita que para alguns autores, o livre mercado diminuiria a possibilidade do Estado diminuir a pobreza e a desigualdade.

Em seu texto Por que há tantas desigualdades sociais no Brasil? Um panorama da riqueza e da pobreza brasileira, Maria Laura Silveira (2005) afirma que os primórdios da globalização no Brasil acontecem ainda na década de 70, quando a modernização transborda das indústrias em direção de áreas, até então, intocadas. Alguns exemplos dessas áreas seriam a mídia, o ensino e o trabalho. Essa modernização seria conduzida pela instalação de complexas redes de comunicação e transportes. Essa unificação do território corresponderia a uma unificação do mercado, guiada sob a luz do capital estrangeiro. "O consumo e o crédito encontram as bases materiais para a sua instalação em quase todo o território" (P.158).

Para Silveira (2005), o Estado deveria subsidiar a melhoria de condições de vida dos mais pobres. Ao invés disto, a globalização o influencia a focar na integração com outros mercados, priorizando a exportação. Esse foco, segundo a autora, traria a "multiplicação da pobreza".

Quando a exportação é empregada como solução necessária, em vez de buscar a melhoria das condições de vida dos mais pobres, ampliando-se a produção e a circulação desnecessária e se aprofunda uma divisão do trabalho igualmente desnecessária. A globalização acelera este processo porque faz parte do seu credo a idéia de que sem exportar é impossível modernizar-se e participar plenamente do mundo 'civilizado'. (...) Uma das conseqüências desse processo é a multiplicação e disseminação da pobreza nas diversas camadas sociais das regiões brasileiras. (...) Subsídios e créditos do Tesouro para auxiliar grandes corporações e bancos são, entre outras, formas legais de violência que, como vemos cotidianamente, ampliam outras modalidades de violência, amiúde ilegais. (P.160)

Com a globalização, essa nova sociedade ficaria, então, marcada por uma maior concentração de renda. Silveira (2005) ainda comparou a classe mais rica em dois anos, 1981 e 1997. Por classe mais rica, a estudiosa entende que se trata das pessoas que possuem renda igual ou superior a 20 salários mínimos. No ano anterior, a porcentagem das pessoas consideradas ricas era de $0,7 \%$ da população com mais de 10 anos de idade e concentrava 15,9\% da renda nacional. Já no ano 
posterior à abertura, a proporção do mesmo grupo subiu para 1,8\% e concentrava $26,4 \%$ do rendimento, algo em torno de US\$34,5 bilhões. A conclusão que ela tira é de o volume de renda do país aumentou, mas os mecanismos de distribuição não. "Em conseqüência, nos últimos anos aumenta o volume da renda e ao mesmo tempo multiplica-se o número de excluídos no Brasil” (P.165). O problema da economia seria estrutural, o excedente seria transformado em lucro apropriado pelo poder privado, não se revertendo em melhorias sociais.

\begin{abstract}
A divisão do trabalho que resulta do neoliberalismo é produtora de pobreza e dívidas sociais. Fundada nos acréscimos técnico-científicosinformacionais e nos mecanismos financeiros, ela é feita da superposição das divisões do trabalho das grandes corporações. É por isso que a divisão do trabalho no país tem um papel ativo na desvalorização dos fazeres e lugares que não perfazem essas necessidades. Daí os mecanismos de exclusão e a produção da pobreza. (P.171)
\end{abstract}

Assim, o pensamento de Silveira (2005) é que a globalização foi e é maléfica ao país. Seria a representação de uma divisão de trabalho ditada pelas grandes corporações e influenciada pelo neoliberalismo. A informação teria papel predominante e propositalmente excluiria algumas regiões em benefício de outras, que tivessem uma demanda pela produção já consolidada ou em vias de se consolidar. Desse modo, não apenas a renda tenderia a se concentrar mais, mas também o fornecimento de bens e serviços tenderia a se concentrar em determinadas regiões. O Estado seria voltado ao interesses das empresas e não para as necessidades da população. Para Silveira, quando o Estado faz a opção pela exportação, acaba por contribuir para a pobreza gerada pela globalização.

Em seu artigo, Impactos do desemprego e da precarização sobre famílias Metropolitanas (2006), Ângela Borges se propõe a analisar as conseqüências de uma suposta crise no mercado de trabalho sobre as famílias de três regiões metropolitanas distintas: Salvador, Belo Horizonte e Porto Alegre. A justificativa é que a análise sob o ponto de vista das famílias traria contribuições importantes para o entendimento dessa crise. Para isso, ela utiliza dados da PNAD em dois períodos distintos, 1995 e 2004. A autora explicita a sua militância anti-globalização logo nos primeiros parágrafos de seu artigo. 
Desde o início dos anos 90, quando os primeiros impactos da reestruturação produtiva e da gestão neoliberal da economia brasileira se fizeram sentir - com o desemprego, a precarização e as acentuadas perdas salariais e de benefícios vitimando milhões de trabalhadores brasileiros -, os estudos e pesquisas sobre as várias dimensões do processo de desestruturação dos mercados de trabalho assumiram um lugar relevante na produção das Ciências Sociais. (P.02)

Neste estudo é possível verificar a existência de uma nova gestão governamental, influenciada pelo neoliberalismo. Para ela, o impacto de uma nova reestruturação produtiva foi indubitavelmente a desestruturação do mercado de trabalho, causando a perda de postos de trabalho junto a perdas salariais.

Ao analisar os resultados da pesquisa quantitativa, a autora percebe que, em primeiro lugar, as famílias numerosas dão lugar a aquelas que possuem no máximo quatro integrantes. Conseqüentemente, o número médio de componentes por família caiu, sendo cerca de três o número médio nas três regiões em 2004. Os arranjos familiares também sofreram mudanças. Houve uma expansão do modelo "mãe e filhos" e "outros tipos de família" em detrimento do modelo tradicional formado pelo casal. Segundo Borges (2006), a inserção da mulher no mercado de trabalho, além de estar associado a uma progressiva mudança cultural, tem relação direta com a queda de rendimento do pai trabalhador. A autora inclusive acredita que essa diminuição da responsabilidade do homem poderia trazer outras conseqüências negativas.

Isto porque a elevação do desemprego e as perdas salariais de homens adultos vêm contribuindo para acelerar a desconstrução do papel do homem provedor, processo que, não raro, resulta em conflitos intrafamiliares, inclusive na violência contra mulher e filhos, na dissolução do vínculo conjugal ou, simplesmente, na fuga das responsabilidades da paternidade. (P.03)

Apesar dessa tendência geral, a pesquisadora notou que Salvador, das três capitais, possui a maior expansão e o maior número de famílias sob o modelo "mãe e filhos". Em 2004, estavam enquadradas neste modelo um quarto das famílias soteropolitanas contra apenas $17 \%$ das porto-alegrenses. 
Para Borges (2006), essa diferença ressalta a maior vulnerabilidade dos trabalhadores da capital baiana frente às transformações em curso, pois seria nesse tipo de arranjo familiar que se encontram as proporções médias mais elevadas de pobres e indigentes. Segundo a estudiosa, existem mudanças nas três estruturas econômicas analisadas. Entretanto, ao mesmo tempo, as diferentes proporções de mudanças nos indicadores apontam para diferentes estratégias de inserção no mercado de trabalho, de acordo com cada região. As três regiões estariam fora do núcleo dinâmico originário da economia nacional, Rio de Janeiro e São Paulo, e teriam processos históricos particulares. Porto Alegre estaria sob influência do Mercosul e estaria passando por um período industrial dinâmico. Belo Horizonte teria estreitado seus laços com o núcleo e estaria dentro do processo chamado de "desconcentração concentrada". Esse mesmo processo teria prejudicado Salvador, que embora tenha recebido investimentos industriais, estes possuíam baixa capacidade de geração de emprego e distribuição de renda.

Dentro da geografia, Santos talvez seja o maior crítico do fenômeno e o seu livro Por uma outra globalização, de 2001, exemplifica, com perfeição, os pontos a serem encontrados nas mais diversas críticas à Globalização. Esta traz efeitos negativos, apesar de se apresentar como benéfica. Essa apresentação seria como um disfarce que prometeria desenvolvimento, mas traria o contrário, acentuando as disparidades.

Um mercado avassalador dito global é apresentado como capaz de homogeneizar o planeta quando, na verdade, as diferenças locais são aprofundadas. (...) Enquanto isso, o culto ao consumo é estimulado. (P.19)

O Estado, quando não é ausente, é visto como a serviço de grandes conglomerados econômicos estrangeiros. Sua função seria facilitar o seu movimento dentro do mercado doméstico.

Fala-se, igualmente, com insistência, na morte do Estado, mas o que estamos vendo é o seu fortalecimento para atender aos reclamos da finança e de outros grandes interesses internacionais, em detrimento dos cuidados com as populações cuja vida se torna mais difícil. (P.19) 
Nota-se que para esses pensadores, fica claro o seu entendimento de que o Estado deve subsidiar a população. Deve ser ele o motor da melhoria de vida dos cidadãos. Finalmente, afirma-se que a globalização é produtora de pobreza.

O desemprego crescente torna-se crônico. A pobreza aumenta e as classes médias perdem em qualidade de vida. $\mathrm{O}$ salário médio tende a baixar. $\mathrm{A}$ fome e o desabrigo se generalizam em todos os continentes. Novas enfermidades como o SIDA se instalam e velhas doenças, supostamente extirpadas, fazem o seu retorno triunfal. A mortalidade infantil permanece, a despeito dos progressos médicos e da informação. A educação de qualidade é cada vez mais inacessível. Alastram-se e aprofundam-se males espirituais e morais, como os egoísmos, os cinismos, a corrupção. (P.19)

Entretanto, pode-se notar que apesar de ser o pensador mais influente, ele não fundamenta o seu trabalho. Em seu livro, não se faz menção a pesquisas estatísticas e nem há tabelas comparativas, ao contrário das autoras citadas anteriormente. Ele não demonstra com base em quais dados e para que período se baseou para afirmar que a mortalidade infantil permanece e que a pobreza aumenta. O texto o Futuro das Megacidades, de 1998, transcreve uma palestra de Milton Santos. Após ser questionado sobre estatísticas, Santos teceu a seguinte resposta.

[...] o economicismo acaba por dar um sério valor aos números e às séries estatísticas. Ora, eu não sei o que fazer com as séries estatísticas. O que é que faço? O que faço com as séries estatísticas é enfeitar o meu texto. ( $P$. 23).

Traçando um paralelo com Almeida (1998), a tese de Santos (2001) seria, se não o melhor, um dos melhores exemplos de pensamento fatalista: a afirmação que o país piora sem nenhuma base empírica.

\section{Pesquisas sobre a pobreza: IPEA}

Em 2006, foi publicada pelo IPEA - Instituto de Pesquisa Econômica Aplicada, uma coletânea denominada Desigualdade de Renda no Brasil: uma análise da 
queda recente. Escrita por diversos autores, ela reuni basicamente estudos voltados para a estimação da queda recente na desigualdade e suas conseqüências para a população mais pobre, e estudos que procuram identificar quais foram os fatores que levaram a essa diminuição. Os estudos citados nesse artigo foram motivados pelo relatório publicado pelo IPEA em agosto de 2006.

Ao analisar os dados da PNAD, percebeu-se que, apesar de a desigualdade de rendimento ter mostrado uma tendência contínua de diminuição desde 1995, em 2001 ela decresce de forma mais acentuada. Em sua análise, os autores consideraram o rendimento domiciliar, o rendimento domiciliar per capita (RDPC), o rendimento mensal das pessoas economicamente ativas (PEA com renda positiva), o rendimento mensal de todas as pessoas (PEA com declaração de rendimento) e o rendimento mensal de todos os trabalhos das pessoas ocupadas com rendimento (POC). Na RDPC, o rendimento domiciliar é dividido entre os ocupantes do domicílio, excluindo pensionistas e empregados domésticos. Na PEA com declaração de rendimento, se incluem aqueles que declararam rendimento nulo. Como até 2003 a PNAD não cobria a área rural da Região Norte, os dados de 2004 e 2005 dessa mesma região foram desconsiderados.

Com esses dados, foi montada a tabela um, que mostra a evolução da desigualdade de renda, utilizando o índice de Gini e T de Theil. Pode-se perceber que a queda dos índices com base na renda domiciliar é pequena até 2001, quando se torna mais realçada. Para as outras três distribuições, apesar do ritmo descadenciado, é clara a tendência de baixa. A análise do T de Theil indica aumento da desigualdade entre pessoas economicamente ativas (PEA) e pessoas ocupadas (POC).

A análise com base em diferentes formas de avaliar a renda sob dois diferentes índices procura demonstrar que mesmo sob diferentes óticas, os números baixaram. Segundo os autores, a desigualdade entre a RDPC e a PEA acontece porque esta última reflete mais diretamente a situação do mercado de trabalho. Os pensionistas, aposentados e crianças estão incluídos na primeira, mas não na segunda forma de analisar a renda. Chama a atenção o fato de que, independentemente do 
rendimento observado, todos possuem uma tendência de redução da desigualdade, como é possível visualizar no gráfico um.

TABELA 1 - EVOLUÇÃO DA DESIGUALDADE DE RENDA NO BRASIL ENTRE 1995 E 2005

\begin{tabular}{ccc|c|c|c|c|c|c}
\hline \multicolumn{3}{c}{ INNO } & \multicolumn{3}{c|}{ INDICE DE GINI PARA } & \multicolumn{3}{c}{ T DE THEIL PARA } \\
\cline { 2 - 9 } & RDPC & PEA & $\begin{array}{c}\text { PEA } \\
\text { TOTAL }\end{array}$ & POC & RDPC & PEA & $\begin{array}{c}\text { PEA } \\
\text { TOTAL }\end{array}$ & POC \\
\hline 1995 & 0,599 & 0,589 & 0,662 & 0,585 & 0,727 & 0,710 & 0,907 & 0,698 \\
1996 & 0,600 & 0,584 & 0,657 & 0,580 & 0,726 & 0,698 & 0,889 & 0,687 \\
1997 & 0,600 & 0,584 & 0,659 & 0,580 & 0,731 & 0,703 & 0,902 & 0,690 \\
1998 & 0,598 & 0,581 & 0,659 & 0,575 & 0,728 & 0,697 & 0,903 & 0,677 \\
1999 & 0,592 & 0,572 & 0,655 & 0,567 & 0,706 & 0,666 & 0,881 & 0,650 \\
2001 & 0,594 & 0,571 & 0,642 & 0,566 & 0,720 & 0,680 & 0,862 & 0,664 \\
2002 & 0,587 & 0,569 & 0,637 & 0,563 & 0,705 & 0,670 & 0,843 & 0,655 \\
2003 & 0,581 & 0,561 & 0,630 & 0,554 & 0,680 & 0,652 & 0,824 & 0,635 \\
2004 & 0,569 & 0,553 & 0,616 & 0,547 & 0,656 & 0,637 & 0,791 & 0,623 \\
2005 & 0,566 & 0,550 & 0,616 & 0,544 & 0,650 & 0,641 & 0,800 & 0,624 \\
\hline
\end{tabular}

Fonte: IPEA (2006)

GRÁFICO 1 - EVOLUÇÃO DO ÍNDICE DE GINI DA DISTRIBUIÇÃO DE RENDA NO BRASIL ENTRE 1995 E 2005.

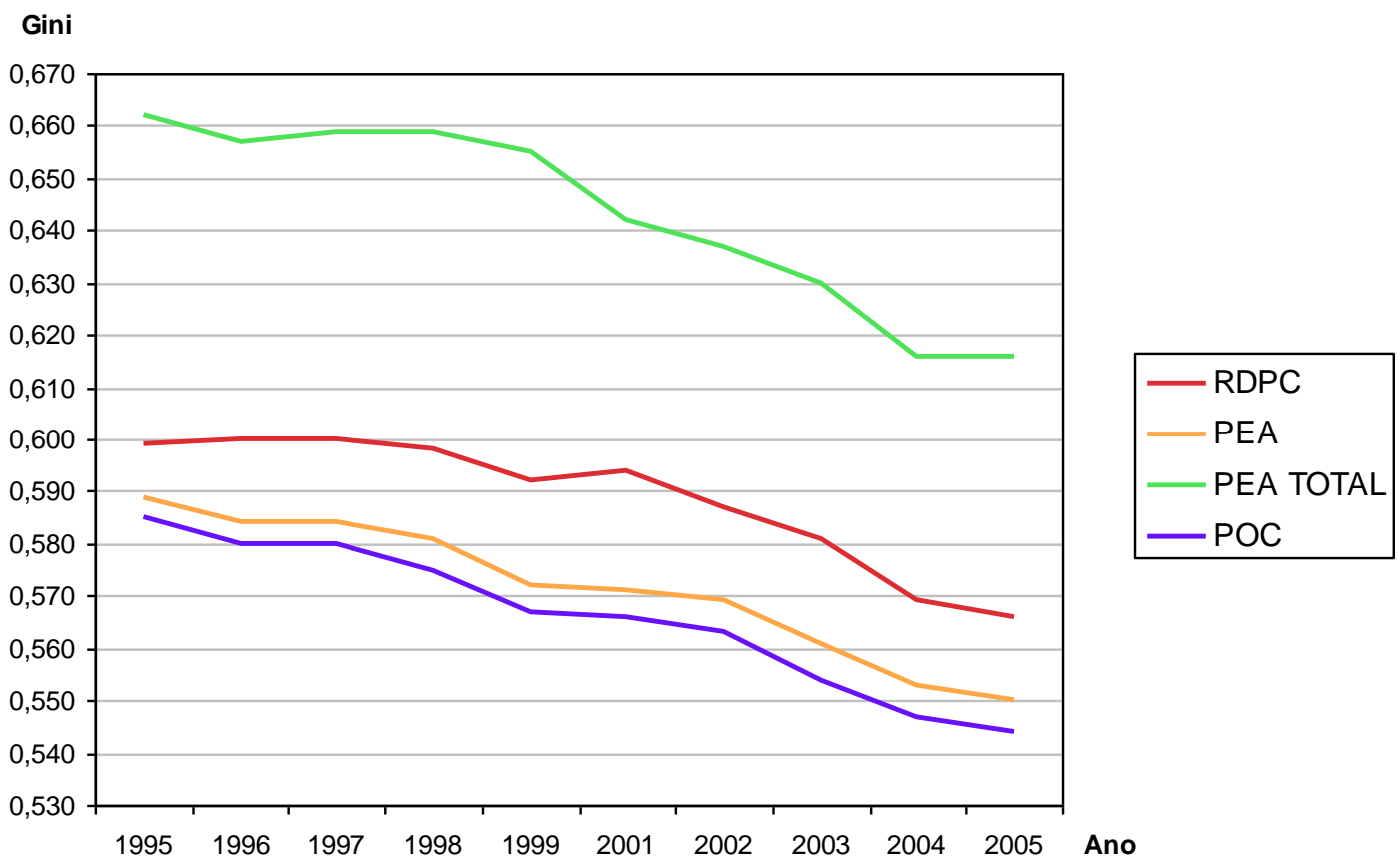

Fonte: IPEA (2006) 
No capítulo dois, os pesquisadores isolaram o coeficiente de Gini e o T de Theil com base na renda familiar per capita e produziram gráficos que abrangem um período maior. A sua intenção é demonstrar a média dos índices nos últimos anos e destacar que em 2005, eles atingiram o seu melhor patamar, desde 1977.

No gráfico dois é possível verificar que, após queda vertiginosa nos últimos anos da década de 70, ao entrar na década de 80 os números demonstraram uma tendência, nem sempre regular, de subida. Essa subida reflete as bruscas flutuações das taxas de inflação da "década perdida" e culmina num violento salto em 1989. Entretanto, é preciso destacar que essa gigantesca inflação pode distorcer o cálculo da renda e da desigualdade. A queda vertiginosa que vem em seguida é resultado da queda relativa da inflação. Depois há uma subida de ajuste, a estabilização e a progressiva queda até 2005. Os resultados demonstram que, durante a fase de estabilidade do Índice de Gini, entre 1993 e 1998, o índice manteve-se acima da média, o que reforça a tese de que a melhora foi mais agressiva a partir de 2001.

GRÁFICO 2 - EVOLUÇÃO DA DESIGUALDADE DE RENDA PER CAPITA NO BRASIL ENTRE 1977 E 2005: COEFICIENTE DE GINI E ÍNDICE DE THEIL

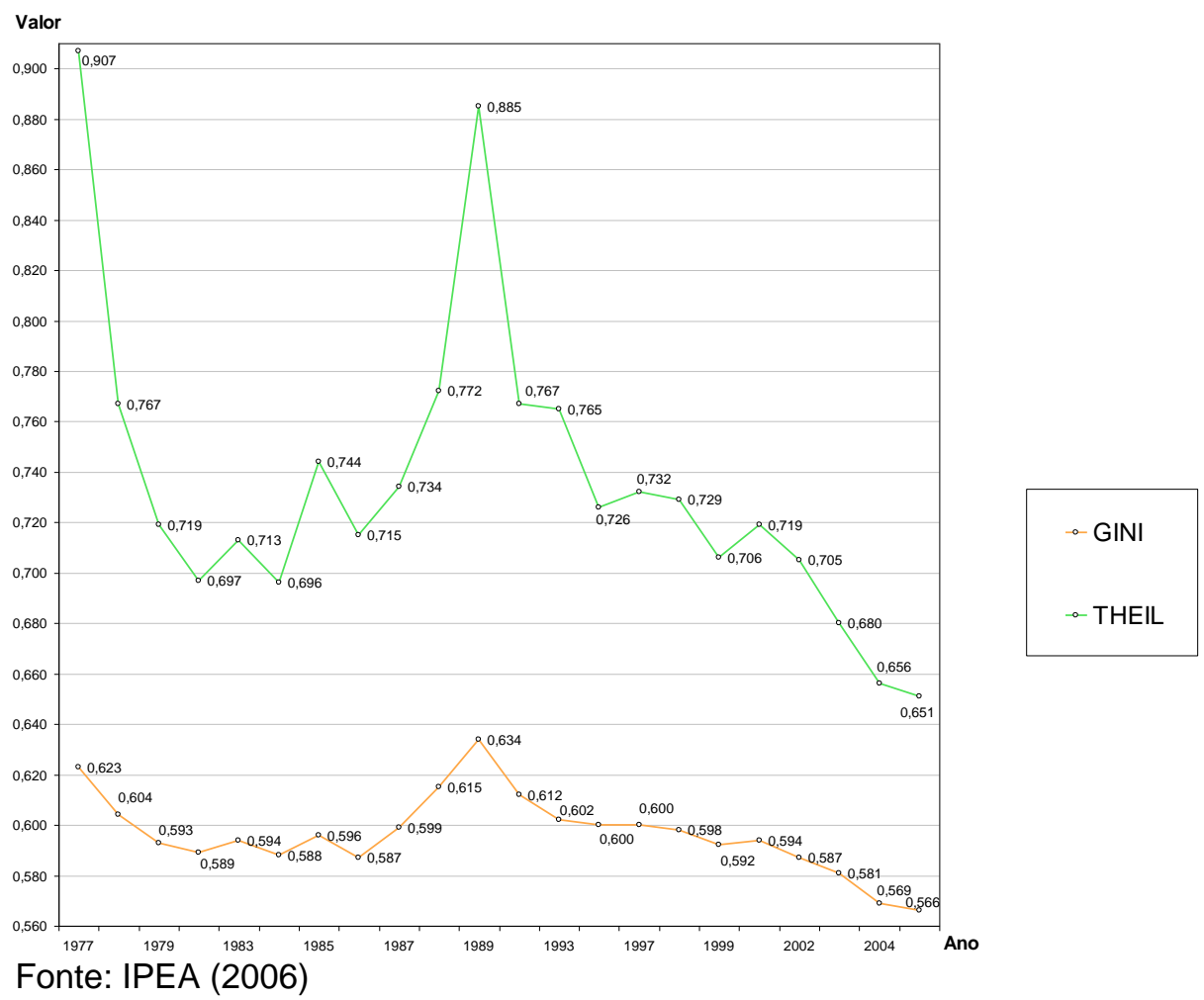


O trabalho conclui que a partir de 1995, houve um processo estável e contínuo de redução de desigualdade, especialmente a partir de 2001. Apesar de que algumas medidas de desigualdade, como o $\mathrm{T}$ de Theil para distribuição de renda por pessoa economicamente ativa, terem aumentado entre 2004 e 2005, o rendimento domiciliar per capita (DPC) indica que comparando 1995 e 2005, há menos pobres e menos ricos no ano mais recente, e que os pobres estão mais longe da miséria absoluta, ou seja, estão menos pobres.

O estudo, então, parte para a análise da distribuição de renda, fator primordial para o entendimento da redução da pobreza. Analisando os dados da PNADs, foi montada a tabela dois. O estudioso percebe que os $10 \%$ mais ricos do país tiveram a sua porcentagem de renda apropriada caindo de 47,2\% em 2001 para 45\% em 2005. O 1\% mais rico apropriava, em $2001,13,8 \%$ da renda nacional. No mesmo ano, metade da população, o 50\% mais pobre apropriava-se de 12,7\%. Em 2005, a inversão: o $1 \%$ mais rico se apropriava de $12,9 \%$, enquanto o $50 \%$ mais pobre se apropriava de $14,2 \%$. Para comparar os valores, o autor utilizou os valores como reais de 2006, com a utilização do INPC como deflator.

TABELA 2 - EVOLUÇÃO DO RENDIMENTO MÉDIO DE SEIS ESTRATOS DA RENDA DOMICILIAR PER CAPITA DO BRASIL ENTRE $2001 \mathrm{E} 2005$

\begin{tabular}{lccccccc}
\hline \multirow{2}{*}{ EXTRATO } & \multicolumn{3}{c}{$R E N D A$ MÉDIA EM R $\$$ DE AGOSTO DE 2006 } & \multicolumn{2}{c}{ VARIAÇAिO } \\
& 2001 & 2002 & 2003 & 2004 & 2005 & $2001-2004$ & $2001-2005$ \\
\hline Quinto mais pobre & 51,1 & 55,7 & 52,7 & 59,3 & 64,8 & 16,0 & 26,6 \\
Segundo quinto & 128,0 & 131,1 & 126,5 & 137,3 & 147,5 & 7,3 & 15,2 \\
Terceiro quinto & 224,6 & 226,9 & 219,2 & 232,8 & 250,1 & 3,7 & 11,4 \\
Quarto quinto & 393,1 & 394,5 & 377,4 & 395,1 & 418,1 & 0,5 & 6,4 \\
Nono décimo & 707,4 & 704,6 & 668,1 & 688,4 & 719,9 & $-2,7$ & 1,8 \\
Décimo mais rico & 2057,5 & 2044,2 & 1891,6 & 1911,9 & 2031,0 & $-7,1$ & $-1,3$ \\
\hline Total & 435,8 & 436,5 & 411,1 & 424,9 & 451,2 & $-2,5$ & 3,5 \\
\hline
\end{tabular}

Fonte: IPEA (2006)

Nessa tabela, dividiu-se a população em cinco grupos para melhor apresentar os resultados da pesquisa sobre as diversas camadas da população, sendo que o 
quinto mais rico foi dividido novamente, obtendo-se os dois décimos mais ricos. Com base na RDPC, a tabela mostra que o rendimento é praticamente o mesmo em 2001 e 2002. Em 2003 ele cai, mas recupera-se em 2004. Em 2005 ele volta a crescer: + 6,2\%. Entre 2001 e 2004, aumentou a renda média dos três quintos mais pobres da população e diminuiu a do quinto mais rico. Os $20 \%$ mais pobres aumentaram seus rendimentos em $16 \%$, enquanto os $10 \%$ mais ricos diminuíram os seus em $7,1 \%$. No capítulo três, os autores se referem à primeira década do século $\mathrm{XXI}$ da seguinte forma: "É razoável afirmar que, da mesma forma que a década anterior foi a da estabilização da inflação, a atual está sendo - até agora - a da redução da desigualdade de renda" (P.130). O gráfico três demonstra que a razão entre os mais pobres e os mais ricos segue a mesma tendência dos índices de pobreza: eles apresentam um histórico de queda em 2001, após um período de estabilidade durante os anos 90 .

\section{GRÁFICO 3 - EVOLUÇÃO DA DESIGUALDADE NA RENDA FAMILIAR PER CAPITA NO BRASIL ENTRE 1977 E 2005}

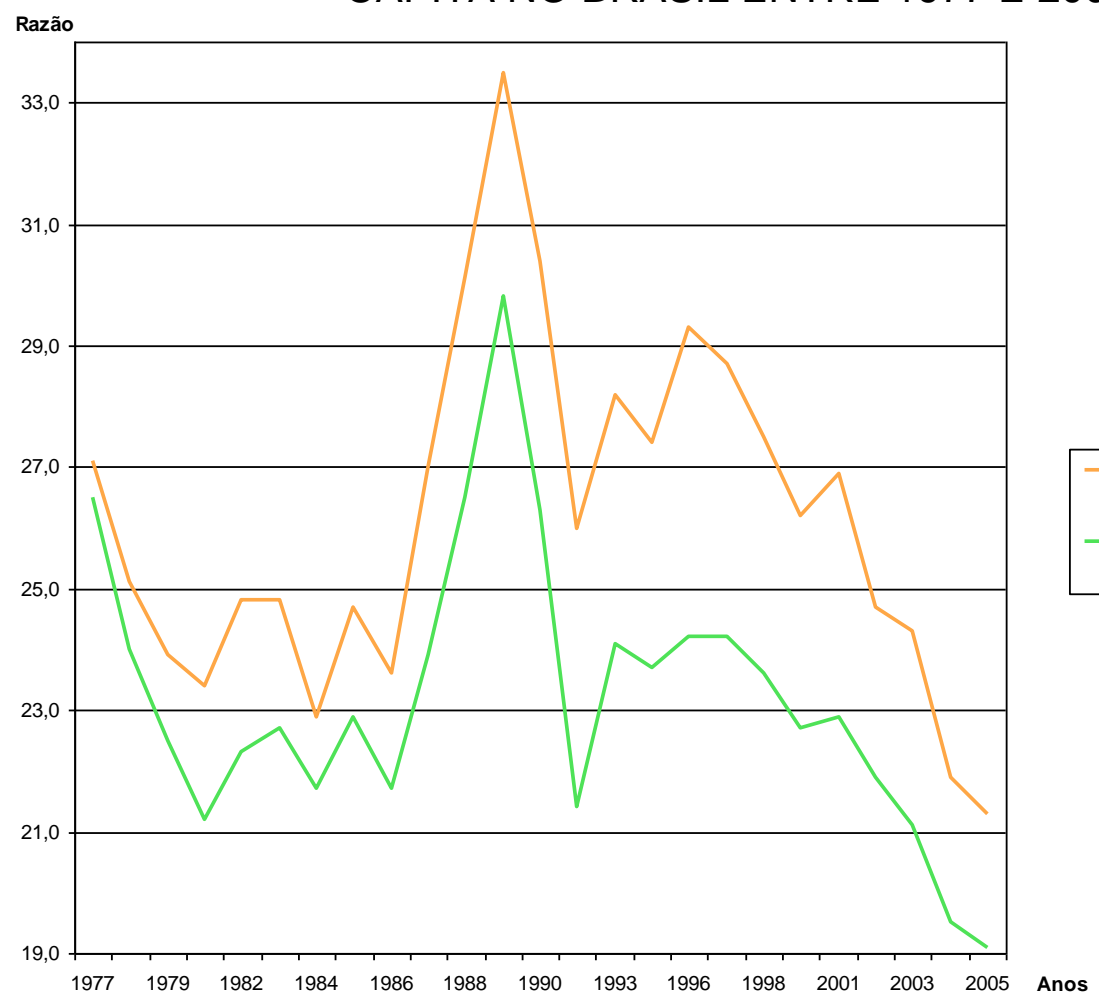

Fonte: IPEA (2006) 
Assim, pode-se concluir que, apesar da estabilização do grau de distribuição de renda nos anos 90, após umas melhora inicial devido ao fim da hiper-inflação, o estágio seguinte foi marcado por uma progressiva e estável queda na razão entre os mais ricos e os mais pobres.

Desde 1992, a insuficiência de renda é abordada no questionário do PNAD, fornecendo séries para o entendimento da miséria. Os pesquisadores continuam a sua análise e se propõe a estudar os movimentos abaixo da linha de miséria. Segundo eles, o período analisado apresenta uma quebra num paradigma brasileiro de épocas anteriores, onde havia uma manutenção contínua de desigualdade.

Conforme o gráfico quatro, na passagem de 1993 a 1995, a proporção de pessoas que viviam abaixo da linha diminui. Em 1993 a porcentagem era 35,3\%. Dois anos depois a porcentagem já era de 28,8\% de brasileiros. Em 2005 a porcentagem chegou a 22,7\%. Assim, entre 2003 e 2005 houve uma queda de $19,18 \%$ de miséria. Destaque também para a queda de $18,47 \%$ no período de 93 a 95. A pesquisa classifica como miserável os indivíduos que vivem com menos de $R \$$ 121,00 por mês, a preços de outubro de 2005 na Grande São Paulo. Essa quantia seria suficiente apenas para a sobrevivência alimentar.

GRÁFICO 4 - PORCENTAGEM DA POPULAÇÃO MISERÁVEL NO BRASIL ENTRE 1992 E 2005.

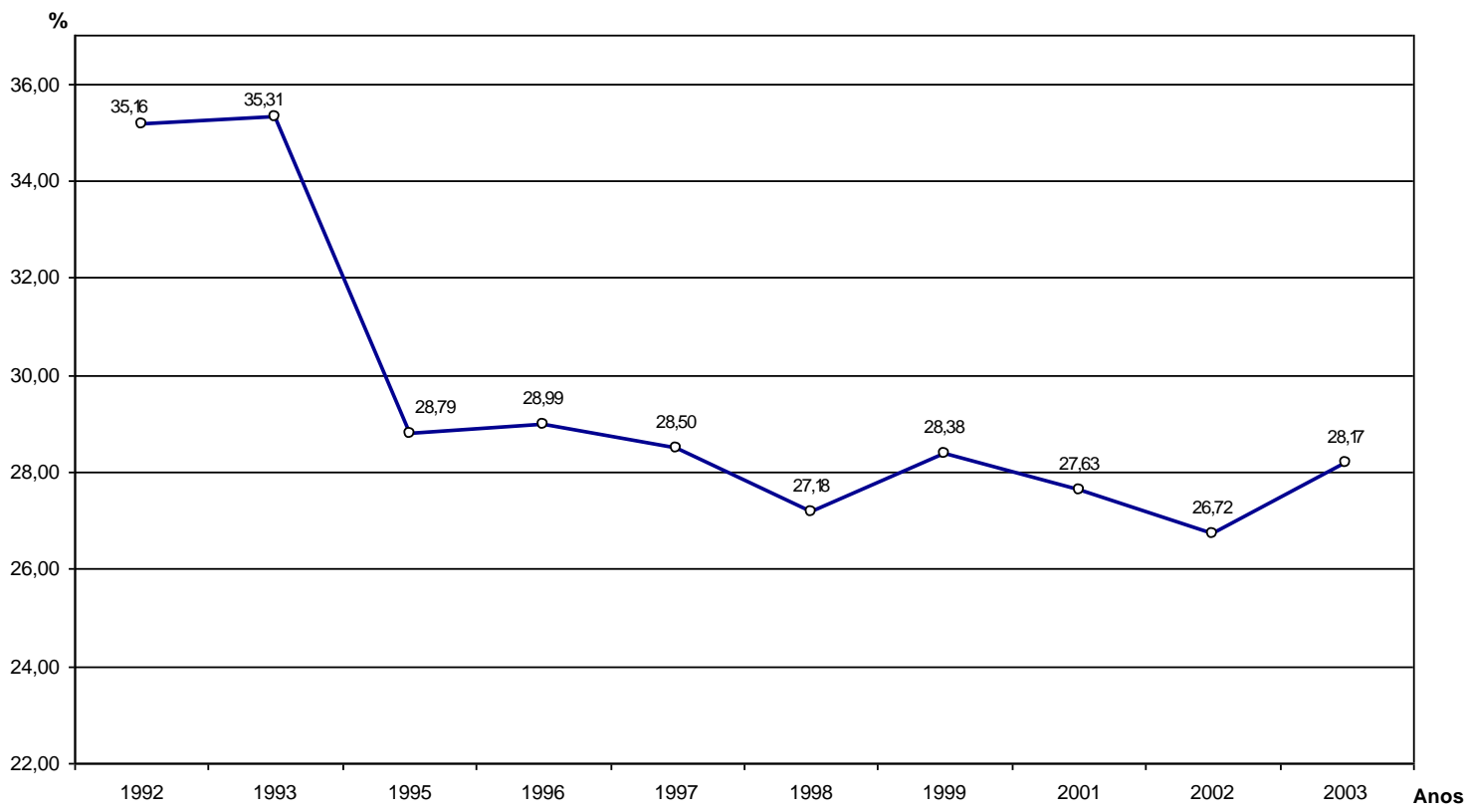


Fonte: IPEA (2006)

Segundo a sua análise, a redução poderia ter sido ainda maior. Se a renda per capita tivesse crescido mais 3\% com uma queda de mais 0,007 ponto no Índice de Gini, a miséria brasileira cairia $8,44 \%$. Em uma projeção futura, mesmo que o país não crescesse, a pobreza poderia manter a sua tendência de diminuição. Segundo os autores, bastaria que nos próximos quatro anos pós 2005, o índice de Gini mantivesse o desempenho do último triênio, quando se observou uma queda de 0,02 no índice.

Os capítulos 2 e 10 da publicação do IPEA dão ênfase no período 2001-2005. Ao analisar a evolução do Índice de Gini para a RDPC, os autores contradizem qualquer tipo de idéia que afirme que a melhora no índice foi pouca. Segundo eles, a queda de magnitude de quase $5 \%$ no índice somente foi superada por menos de um quarto dos 74 países que se tem informações sobre a evolução deste indicador. Já o nível de crescimento da renda per capita, entre os anos de 1990 e 2003, dos 10\% mais pobres é próxima a da China e maior que 99\% dos países sobre os quais se têm dados a respeito. Já quanto aos $20 \%$ mais pobres, o desempenho foi quase o mesmo: apenas $2 \%$ dos países considerados obtiveram uma taxa mais acelerada.

\begin{abstract}
Essas reduções nos graus de pobreza e de extrema pobreza independem da linha selecionada e podem ser consideradas acentuadas segundo uma variedade de critérios. Em primeiro lugar, porque essa taxa de redução da extrema pobreza é quatro vezes mais acelerada do que o necessário para cumprir com a primeira meta de desenvolvimento do milênio. A essa velocidade, seria possível reduzir a extrema pobreza à metade em seis anos, enquanto a primeira meta de desenvolvimento do milênio estabelece um prazo de 25 anos. Em segundo lugar, porque essas taxas de redução na pobreza e na extrema pobreza são mais acentuadas do que as que se observam em todos os países latino-americanos para os quais se tem a informação correspondente, à exceção do México. (P.340)
\end{abstract}

Apesar do ritmo rápido, os próprios autores confirmam que o país continua ocupando uma posição desfavorável na tabela que mostra a desigualdade de renda com base no índice de Gini. Quanto à renda per capita, 64\% dos países têm renda inferior à brasileira e, se analisarmos apenas o quinto mais pobre, 43\%. Para que 0 desempenho apontado pela renda média dos $20 \%$ mais pobres fosse igual ao 
desempenho da renda média per capita, seria necessário que a renda dos mais pobres praticamente dobrasse. Nesse cenário, os $20 \%$ mais pobres teriam a mesma renda dos $20 \%$ mais pobres da Tunísia, o que seria segundo os próprios autores, “... o mínimo que se poderia esperar do combate à desigualdade no País".P.112.

Assim, os autores concluem que, apesar do pequeno crescimento da renda per capita brasileira nos últimos anos, este se localizou quase que integralmente nos segmentos de renda dos mais pobres. Esse fato seria resultado de um processo de crescimento com equidade cuja principal característica é estar atrelado com reduções no grau de desigualdade.

Em suma, o grau de desigualdade do País permanece extremamente elevado. Mesmo mantido o acelerado progresso, serão necessárias ainda mais de duas décadas para que nossa desigualdade se alinhe à dos demais países com o mesmo nível de desenvolvimento. Portanto, o sucesso recente deve ser encarado apenas como um primeiro passo de uma longa jornada. (P.113)

Infere-se que os resultados apurados pela pesquisa do IPEA apontam que houve uma queda recente da desigualdade brasileira. Durante os anos 80 , os índices de desigualdade, como o Índice de Gini, por exemplo, atingiram patamares bastante elevados. Nos anos 90, após o Plano Real, houve uma queda nos índices simultaneamente ao aumento da renda dos mais pobres. Depois os índices se ajustaram e subiram um pouco, para em seguida se manterem estáveis, com uma leve tendência à queda. A queda tornou-se mais agressiva a partir de 2001, quando se transformou num movimento consistente e contínuo. Essa queda é resultado do aumento da renda dos mais pobres e de uma diminuição nos rendimentos dos mais ricos. Apesar de o Brasil ainda ocupar a parcela inferior da tabela dos países com menos desigualdade, a miséria e a pobreza, ao contrário do que pregavam diversas previsões pessimistas, diminuiu nos últimos anos. 


\section{Pesquisas sobre a pobreza: PNUD}

O PNUD constitui-se no Programa das Nações Unidas para 0 Desenvolvimento. Segundo o site oficial, ele se estende por 166 países e o seu foco central é o combate à pobreza. Em conjunto com o IBGE e com IPEA, foi desenvolvida a ferramenta "Atlas do Desenvolvimento Humano no Brasil", um programa de computador alimentado por dados de Censos demográficos onde é possível fazer consultas e comparações de diversos indicadores.

Utilizando essa ferramenta, foi construído o gráfico cinco, onde é possível observar que em todas as regiões do Brasil, a esperança de vida subiu. Na média nacional, o número de anos subiu de 64,80 em 1990 para 68,64 anos em 2000. Nota-se também que a região que mais melhorou nesse quesito foi justamente a Nordeste, tantas vezes usada como exemplo para demonstrar a pobreza: de 59,97 para 64,83 anos. Ela ainda é a mais atrasada nesse quesito, mas entre 1991 e 2000, obteve o maior crescimento, 4,86 contra 3,68 anos da região Sul.

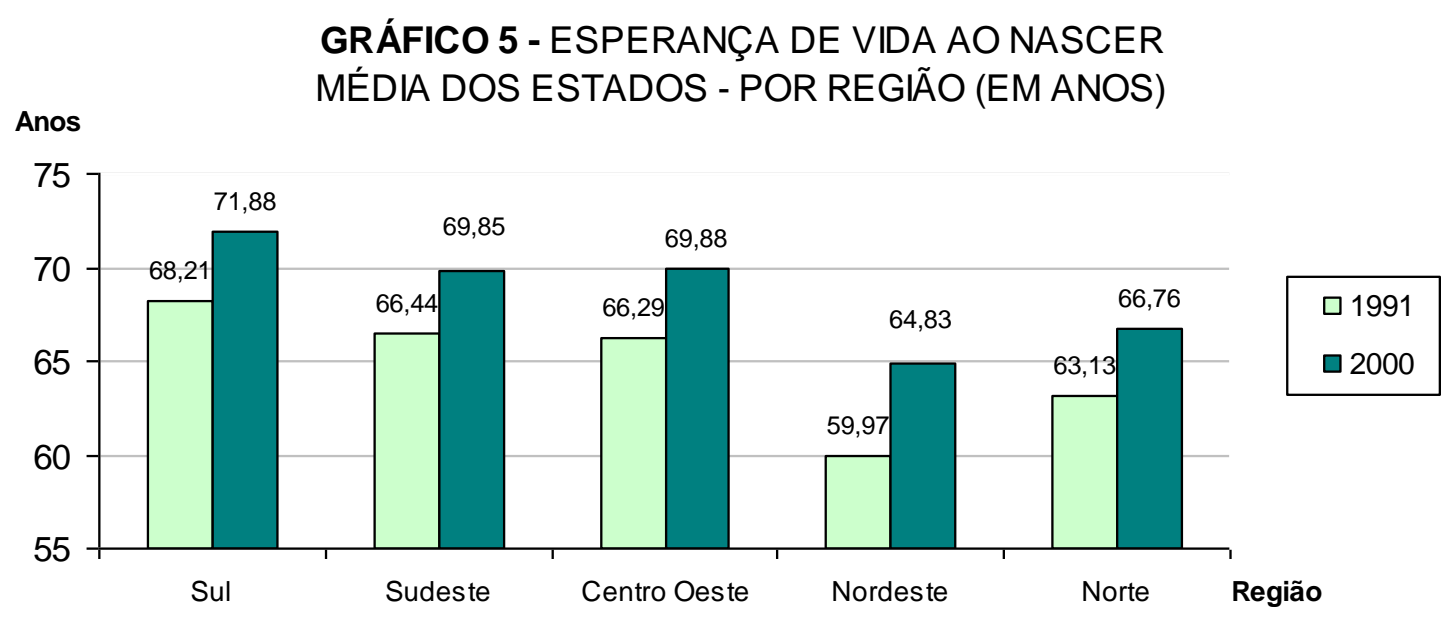

Fonte: PNUD - Atlas do Desenvolvimento Humano no Brasil (2009)

O gráfico seis demonstra que a variável alfabetismo também evoluiu em todo o país, de 79\% em 1991 para 86\% em 2000. Mais uma vez, a região que obteve o maior crescimento foi o Nordeste, com um aumento de $12 \%$ de população alfabetizada, de $61 \%$ para $73 \%$. Apesar da melhora, ainda existe um longo caminho 
para que essa região atinja o patamar da região Sul, que em 2000 apresentava cerca de $92 \%$ de sua população alfabetizada.

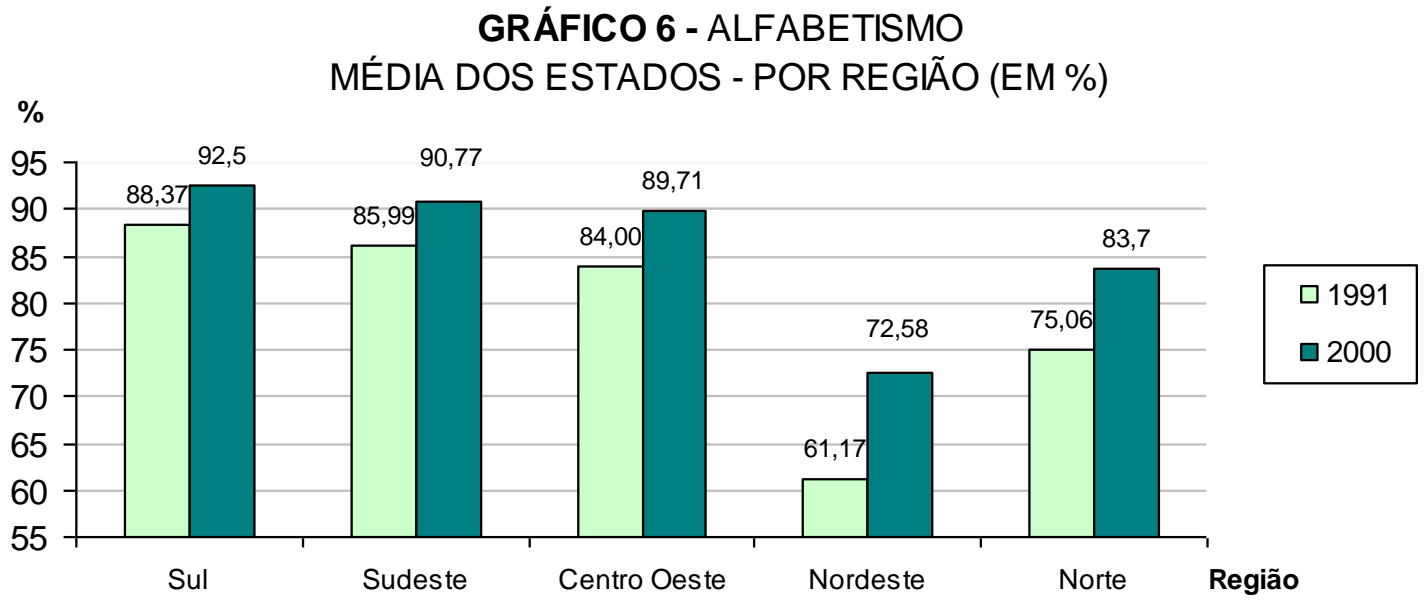

Fonte: PNUD - Atlas do Desenvolvimento Humano no Brasil (2009)

O item analisado pelo gráfico sete é a mortalidade até cinco anos de idade. Logo, a primeira vista destacam-se os altos índices do Nordeste. Apesar da queda de 101 óbitos para 70, no ano de 2.000 para cada 1.000 nascimentos, este número ainda é pior que o pior resultado das outras regiões em 1991. Entretanto a queda vertiginosa ajudou o país a baixar a média nacional de 55 para 37 óbitos de crianças até cinco anos de idade a cada mil nascimentos.

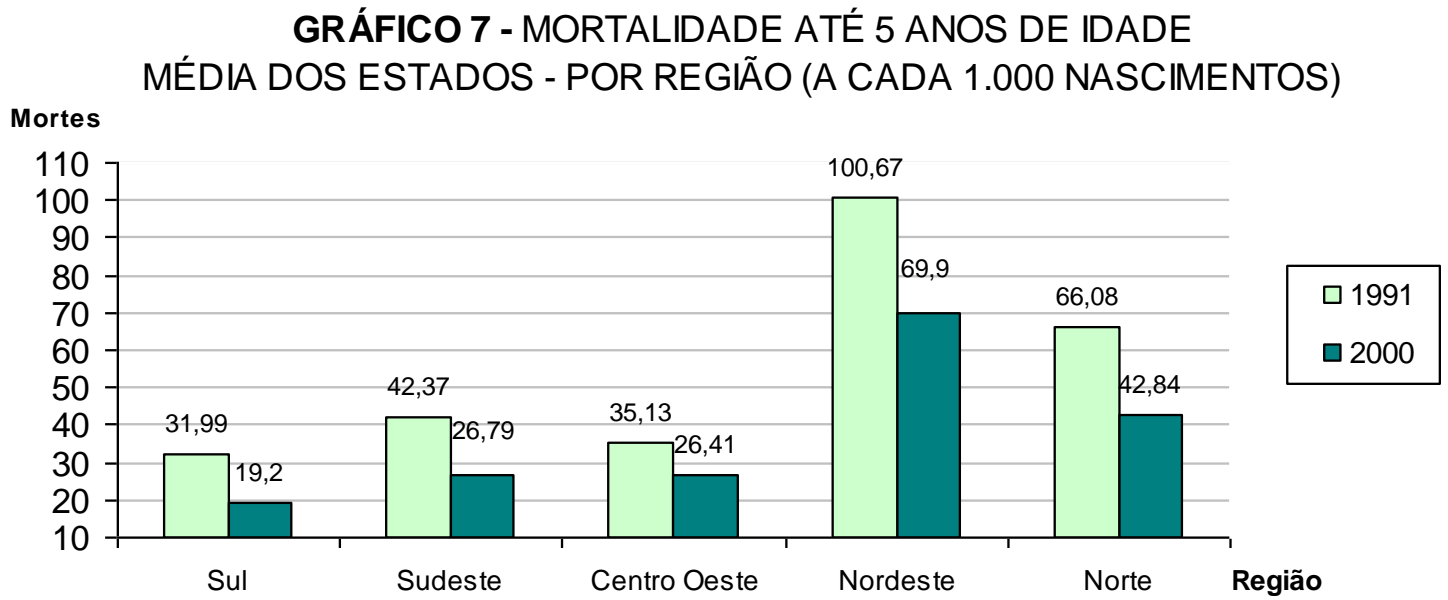

Fonte: PNUD - Atlas do Desenvolvimento Humano no Brasil (2009) 
No item População entre 18 e 22 anos que frequentam curso superior, apresentado no gráfico oito, um dos destaques positivos é a região centro-oeste. De $10 \%$ o índice pulou para $22 \%$ em 2000, graças ao desempenho do Distrito Federal que, em 1991, apresentava a marca de 18,65\% e em 2000 aumentou para 33,44\% 0 número de jovens no ensino superior. O outro destaque é a região sul que também teve um aumento considerável nesse intervalo de tempo: de 12,48\% passou a $25,97 \%$, liderando o ranking nacional. Já a região Nordeste melhorou de 5,77\% para $10,27 \%$, uma melhora lenta, ainda bastante longe da porcentagem de outras regiões.

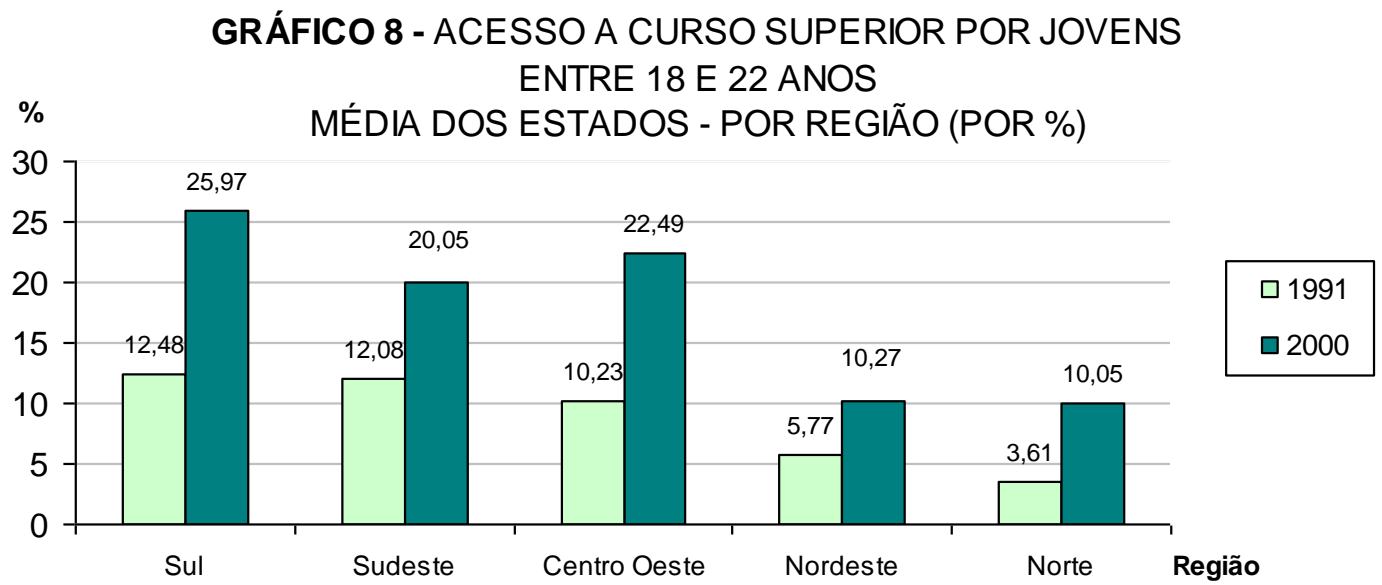

Fonte: PNUD - Atlas do Desenvolvimento Humano no Brasil (2009)

Comparando o ano de 1991, onde o país ainda estava nos primeiros passos de sua inserção no mercado global, com o ano de 2000, já interagindo no mercado internacional, percebe-se que praticamente todos os itens sofreram algum tipo de evolução. A percepção da análise é quase a mesma do que a pesquisa do PNAD, o país continua muitos números atrás dos países desenvolvidos, mas a sua melhora, do ponto de vista do PNUD, não é discreta. A região Nordeste aparece sempre em desvantagem em relação às outras regiões, mas o seu grau de evolução em comparação com o de outras é quase sempre o maior, o que demonstra que as mudanças ocorridas no período 1991-2000 não foram prejudiciais a sua população. 


\section{CONCLUSÃO}

O conceito de globalização, apesar de estar em voga em diversas discussões acadêmicas e não acadêmicas, ainda é bastante controverso (LASTRES, 1997). Entretanto, existem algumas concordâncias em torno do termo. Ao analisá-las, pode-se concluir que a globalização pelo prisma mais comumente utilizado, é um fenômeno sócio-econômico (GONCALVES, 1999) ocorrido no fim do século passado que coincide com a hegemonia do modo econômico capitalista, trazendo os países para um palco comercial internacional. A participação nesse palco é possível graças à adoção de idéias tidas como economicamente liberais; por isso a vinculação da globalização com o capitalismo (PRADO, 2003).

Entendido dessa forma, a inserção do Brasil na Globalização foi intensificada com a mudança do modelo econômico "nacional-desenvolvimentista" para um modelo mais próximo da idéia de "integração competitiva" (DINIZ, 2000). Enquanto o primeiro reservava o lugar de propulsor de modernização ao Estado, o segundo cedia o mesmo lugar ao mercado. A sua implementação aconteceu progressivamente durante os primeiros anos da década de 1990 e se traduziu em diversas formas de abertura econômica, como a redução de barreiras tarifárias a produtos estrangeiros e a privatização de estatais.

A pobreza a princípio estava ligada à sobrevivência básica do indivíduo e se referia principalmente à sua alimentação. Como a vida humana progressivamente se tornou mais complexa, as suas necessidades também se tornaram mais complexas. Além da alimentação, variáveis como habitação, vestuário e saúde passaram a ser computadas. A dificuldade de quantificar a pobreza reside no fato de se estipular um mínimo de produtos que seja aplicável a toda hetereogenidade da população. Nesse sentido, a pobreza relativa pode dar subsídios importantes à compreensão do fenômeno: os índices de Gini e o T de Theil medem a distribuição de renda dentro de uma sociedade, permitindo comparações entre diferentes épocas e países. Todos os índices possuem limitações, mas a sua utilização permite uma 
compreensão mais próxima da realidade da população, além de permitir a construção de estudos genuinamente científicos.

Existem diversos trabalhos que criticam a globalização. Ligada à mudança de paradigma econômico brasileiro nos anos 90, os trabalhos pregam que a situação do país está piorando, sob diferentes prismas. Em comum nas suas análises, a afirmação de que a globalização é produtora de pobreza.

A primeira constatação é que, apesar de ser uma variável constante, poucos autores conceituam o que seria a pobreza. A simples análise da renda per capita, como faz Ângela Borges, não pode ser entendida por si só como indicador de qualidade de vida, sem uma análise do contexto onde está inserida. Uma análise desse tipo poderia mascarar, por exemplo, uma piora na distribuição de renda do país. Por sua vez, Silveira classifica como pertencentes à classe mais rica aqueles que ganham uma renda igual ou superior a 20 salários mínimos. Depois, ela verifica que o percentual da população que pertence a essa classe aumentou. Com isso, ela conclui que o volume de renda pode ter aumentado, mas a distribuição, não. Este pensamento mostra uma dificuldade metodológica na sua conceituação de pobreza. Estipular que uma pessoa rica é aquela que ganha mais de 20 salários mínimos, acarretaria no problema de definição da pobreza absoluta, já que os valores estariam à mercê de um juízo humano definidor.

Isto posto, percebe-se nos trabalhos críticos o que Alberto Carlos de Almeida (1998) já havia constatado: a pouca ou, no caso de Milton Santos, nenhuma base empírica para provar suas afirmações. A que se destacar como exemplo, a análise de Borges que, quando percebe em sua tabela o aumento de famílias chefiadas por mulheres junto a uma suposta diminuição da renda, conclui que "perdas salariais de homens adultos vêm contribuindo para acelerar a desconstrução do papel do homem provedor, processo que, não raro, resulta em conflitos intrafamiliares, inclusive na violência contra mulher e filhos, na dissolução do vínculo conjugal ou, simplesmente, na fuga das responsabilidades da paternidade” (Sic). Em nenhum lugar do seu artigo é mencionada nenhuma pesquisa quanto à violência contra a 
mulher ou algo similar. Assim, uma frase como esta não poderia ser levada em conta do ponto de vista científico, trataria de um achismo ${ }^{2}$.

O trabalho de Milton Santos, Por uma outra globalização (2001), é o maior exemplo de falta de base empírica, pois praticamente não mostra estatísticas. Santos afirma que a pobreza aumenta, o salário médio tende a baixar, a mortalidade infantil permanece e a educação é inacessível. Ele vai além da análise puramente científica e afirma que a globalização é perversa, inclusive faz menção a males espirituais e morais. Assim, no que tange a provar que a globalização traz pobreza, o seu trabalho estaria mais para uma interpretação ideológica tendenciosa do para um trabalho científico, pois contraria a base da ciência cartesiana, as quatro regras do método científico: verificar, analisar, sintetizar e enumerar. Assim, torna-se compreensível quando Milton Santos diz que: "é um equívoco querer definir um mundo a partir do princípio da realidade".(p. 21).

Para testar a afirmação de que a globalização traz pobreza, foram demonstrados diversos gráficos com base em estudos do IPEA e em tabelas produzidas pelos PNUD. Verificou-se que, comparando-se 1991 com 2000, a mortalidade infantil, assim como o índice de anafalbetismo, diminuiu. Ao mesmo tempo, a expectativa de vida e o acesso à educação superior aumentaram. Por sua vez, a pesquisa do IPEA demonstrou que, em se tratando de distribuição de renda, o país permanece entre os piores do mundo, entretanto o ritmo da evolução ocorrida durante entre meados dos anos de 1990 até 2005 foi um dos mais expressivos. A melhora da distribuição de renda afetou principalmente os mais pobres.

Uma vez colocados em confronto, os críticos versus pesquisas estatísticas, a conclusão final deste artigo é que a afirmação de que a globalização traz a pobreza é falsa. A insistência dos autores analisados em ignorar os dados empíricos, que

\footnotetext{
${ }^{2}$ Segundo o Dicionário Michaelis (1998), achismo é "(achar+ismo) sm gír Tendência em avaliar as situações segundo as próprias opiniões ou intenções, muitas vezes sem justificação".

pobreza é falsa. A insistência dos autores analisados em ignorar os dados empíricos, que demonstram a falácia de suas teorias, é devido, provavelmente, a pressupostos puramente ideológicos. As suas teorias poderiam ser válidas se houvesse uma outra proposta de conceituação de pobreza. Na falta destas, pode-se afirmar que a inserção do Brasil na globalização, através da mudança do seu direcionamento econômico nos anos 90 , não aumentou a pobreza. Pelo contrário, o que houve foi, ainda que em ritmo lento, mas constante, uma evolução matematicamente comprovada dos indicadores sociais do Brasil.
} 
demonstram a falácia de suas teorias, é devido, provavelmente, a pressupostos puramente ideológicos. As suas teorias poderiam ser válidas se houvesse uma outra proposta de conceituação de pobreza. $\mathrm{Na}$ falta destas, pode-se afirmar que a inserção do Brasil na globalização, através da mudança do seu direcionamento econômico nos anos 90, não aumentou a pobreza. Pelo contrário, o que houve foi, ainda que em ritmo lento, mas constante, uma evolução matematicamente comprovada dos indicadores sociais do Brasil.

\section{REFERÊNCIAS}

ALBUQUERQUE, E. S. (org). Et al. Que Pais é esse? : pensando o Brasil contemporâneo. São Paulo: Globo, 2005.

ALMEIDA, Alberto Carlos. O BRASIL NO FINAL DO SÉCULO XX: UM CASO DE SUCESSO. Dados, Rio de Janeiro, v. 41, n. 4, 1998 . Disponível em: <http://www.scielo.br/scielo.php?script=sci_arttext\&pid=S001152581998000400004\& Ing=en\&nrm=iso>. Acesso em: 23 de Novembro de 2009.

BORGES, Ângela. Impactos do desemprego e da precarização sobre famílias metropolitanas. Revista Brasileira de Estudos de População, v. 23, n.2. São Paulo, 2006.

CRESPO, A. P. A., GUROVITZ, E. A pobreza como um fenômeno multidimensional. ERA - Eletrônica. São Paulo: Fundação Getúlio Vargas, 2005.

DINIZ FILHO, Luiz Lopes. A dinâmica regional recente no Brasil: desconcentração seletiva com "internacionalização" da economia nacional. São Paulo: Tese (Doutorado) - USP/Programa de Pós-Graduação em Geografia Humana 2000.

FIÚZA, Guilherme. 3.000 dias no bunker. Rio de Janeiro: Record,1ํㅡ ed., 2006.

IANNI, Octavio. Globalização: novo paradigma das ciências sociais. Estudos Avançados, IEA/USP: vol.8, n.21, pp. 147-163. 1994

IPEA (org). Et Al. Desigualdade de renda no Brasil: uma análise da queda recente Brasília: Ipea, 2006

KAYANO, J.; CALDAS, E. L. Indicadores para o diálogo. São Paulo: Pólis, 2001.

LASTRES, H. M. M. A globalização e o papel das políticas de Desenvolvimento industrial e tecnológico. Texto para Discussão n. 519. Brasília: IPEA, 1997.

MICHAELIS Pequeno Dicionário da Língua Portuguesa. São Paulo: Cia Melhoramentos, 1998. 
PRADO, L. C. D. Globalização: notas sobre um conceito controverso. Rio de Janeiro: IE-UFRJ, 2003.

PNUD. Atlas do Desenvolvimento Humano no Brasil. Disponível em: <http://www.pnud.org.br/atlas/>. Acesso em 12 de Novembro de 2009.

ROCHA, S. Pobreza no Brasil: afinal do que se trata. Rio de Janeiro: Fundação Getúlio Vargas, 2003.

Congresso Brasileiro de Sociologia. XIV, 2009, Rio de Janeiro. O futuro das megacidades. São Paulo, 2009.

SANTOS, Milton. Por uma outra globalização: do pensamento único à consciência universal. São Paulo: Record, 2001.

SEN, Amartya K. Desenvolvimento como Liberdade. São Paulo: Cia das Letras, 2000.

S.A. Dicionário Essencial Latim Potuguês. Portugal: Ed. Porto; 2001.

(Recebido em maio/2010. Aceito em Setembro/2010) 